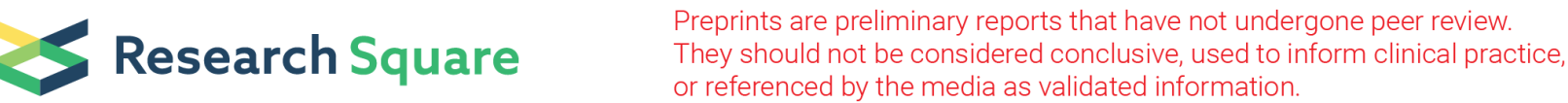

\section{Blood Transfusion Had No Influence on the 5-year Biochemical Recurrence After Robot-assisted Radical Prostatectomy: A Retrospective Study}

\section{Jiwon Han}

Seoul National University Bundang Hospital

\section{Young-Tae Jeon}

Seoul National University Bundang Hospital

Jung-Hee Ryu

Seoul National University Bundang Hospital

Ah-Young Oh

Seoul National University Bundang Hospital

\section{Hwanik Kim}

Seoul National University Bundang Hospital

\section{Yu Kyung Bae}

Seoul National University Bundang Hospital

Chang-Hoon Koo ( $\nabla$ vollock9@gmail.com )

Seoul National University Bundang Hospital

\section{Research Article}

Keywords: Biochemical recurrence, Red blood cell transfusion, Robot-assisted laparoscopic radical prostatectomy, Prostate cancer

Posted Date: August 3rd, 2021

DOI: https://doi.org/10.21203/rs.3.rs-720315/v1

License: (c) (1) This work is licensed under a Creative Commons Attribution 4.0 International License. Read Full License

Version of Record: A version of this preprint was published at BMC Urology on November 17th, 2021. See the published version at https://doi.org/10.1186/s12894-021-00926-0. 


\section{Abstract}

\section{Background}

Although red blood cells (RBC) transfusion is known to be significantly associated with biochemical recurrence in patients undergoing open prostatectomy, its influence on biochemical recurrence after robotassisted laparoscopic radical prostatectomy remains unclear. Therefore, this study aimed to validate the effect of RBC transfusion on the 5-year biochemical recurrence in patients undergoing robot-assisted laparoscopic radical prostatectomy.

\section{Methods}

This study retrospectively analyzed the medical records of patients who underwent robot-assisted laparoscopic radical prostatectomy at single tertiary academic hospital between October 2007 and December 2014. Univariate and multivariate Cox proportional hazard regression analysis was performed to identify any potential variables associated with 5-year biochemical recurrence.

\section{Results}

A total of 1311 patients were included in the final analysis. Of these, 30 patients $(2.3 \%)$ were transfused with RBC either during robot-assisted laparoscopic radical prostatectomy or during their hospital stay, which corresponded to 5-year biochemical recurrence of $15.7 \%$. Multivariate Cox proportional hazard regression analysis showed that RBC transfusion had no influence on the 5-year biochemical recurrence. Variables including pathologic T stage (Hazard ratio [HR] 3.5, 95\% confidence interval [Cl] 2.4-5.1 $p<$ 0.001 ), N stage (HR 2.3, 95\% Cl 1.5-3.7, $p<0.001$ ), Gleason score (HR 2.4, 95\% Cl 1.8-3.2, $p<0.001$ ), and surgical margin (HR 2.0,95\% Cl 1.5-2.8, $p<0.001$ ) were independently associated with the 5-year biochemical recurrence.

\section{Conclusions}

RBC transfusion had no significant influence on the 5-year biochemical recurrence in patients undergoing robot-assisted laparoscopic radical prostatectomy.

\section{Background}

Robot-assisted laparoscopic radical prostatectomy (RARP) is widely used to treat prostate cancer [1]. Advantageously, RARP reduces blood loss, lowers postoperative pain, leads to fewer complications, and promotes better functional outcomes, when compared to conventional approaches [2-4]. In addition, RARP provides better pathological and oncological outcomes when compared to laparoscopic prostatectomy [5].

One common benchmark for evaluating treatment efficacy is biochemical recurrence (BCR), which is used as a surrogate marker for prostate cancer [6]. The 5-year BCR after RARP is reported to be approximately 
$14 \%$ [7]. By contrast, the 5-year BCR after open prostatectomy is reported to be substantially higher, between $20 \sim 40 \%$ [8]. Previous work has identified preoperative prostate specific antigen (PSA), pathologic T stage, surgical margin, as independent predictors of 5-year BCR following open prostatectomy [6]. Moreover, a recent meta-analysis showed that blood transfusion increased the 5-year BCR in patients undergoing open prostatectomy [9]. However, it has not yet been established whether blood transfusion can increase the 5-year BCR in patients undergoing RARP. Therefore, this study aimed to evaluate the effect of blood transfusion on the 5-year BCR in patients undergoing RARP.

\section{Materials And Methods Ethics statement}

This retrospective study was approved by the Institutional Review Board of Seoul National University Bundang Hospital (SNUBH; Approval number: B-2005/615 - 105). Given the retrospective design, the need for informed consent was waived.

\section{Population}

We examined the electronic medical records of patients who were diagnosed with prostate cancer and underwent RARP at SNUBH between October 2007 and December 2014. RARP has been performed in our institution using the da Vinci Surgical System since October 2007. We excluded patients who received radiation therapy or hormonal treatment prior to surgery. Patients whose baseline or postoperative PSA data were missing or incomplete, were also excluded. We also excluded patients whose RARP was converted to open surgery.

\section{Data collection and outcomes}

Blood transfusion data were retrieved from electronic medical records of SNUBH and used to evaluate the efficacy of transfusion. Perioperative transfusion was defined as red blood cells (RBC) transfusion either during RARP or within the postoperative hospital stay. RBC was transfused according to the clinical decision of physicians. The demographic (age and body mass index), clinical, and pathological data of patients were collected as covariates. Collected clinical data included American society of anesthesiologists physical status, smoking history, main anesthetic agents, the administration of intraoperative fluid, estimated blood loss during surgery, duration of surgery and anesthesia, and length of hospital stay. Pathologic evaluation of the specimens was consistently performed by urologic pathologists. Pathologic T stage, N stage, margin status, and Gleason score were collected.

BCR was defined as two consecutive serum PSA level of $\geq 0.2 \mathrm{ng} / \mathrm{mL}$. The initial postoperative PSA was evaluated after 6 weeks. Thereafter, PSA was assessed every 3 months for the first year, and every 6 months during the subsequent 4 years.

\section{Statistical analysis}


Continuous variables were presented as median with interquartile ranges (IQR), categorical variables were presented as number with percentage. Univariate Cox proportional hazard regression analysis was performed to identify any potential variables associated with the 5-year BCR. Subsequently, variables with a $p$-value $<0.1$ in univariate analysis were selected for multivariate Cox proportional hazard regression analysis using forward selection step. In regression analyses, we categorized the pathologic $T$ stage as < pT3 or $\geq$ pT3, and the Gleason score as $<8$ or $\geq 8$. All statistical analyses were performed using SPSS 24. A $p$ value $<0.05$ was considered statistically significant.

\section{Results}

A total of 1341 patients underwent RARP between October 2007 and December 2014 at SNUBH. Among them, 12 patients were excluded due to a lack of preoperative or postoperative PSA data. An additional 15 patients were excluded for receiving radiation therapy or hormonal treatment prior to surgery. Finally, three additional patient was excluded because they were converted from RARP to the open technique or they received re-operation before discharge. As such, a total of 1311 patients were included in the final analysis (Fig. 1).

Demographic characteristics are summarized in Table 1. Among 1311 patients, 30 patients (2.3\%) were transfused with RBCs during RARP or the hospital stay. The median follow-up period after RARP was 102 [IQR 60-146] months, and the 5-year BCR was $15.7 \%(n=206)$. The median time to BCR was 9.8 [IQR 3.4-30.1] months. 
Table 1

Clinical and pathological characteristics of included patients $(n=1311)$

\section{Variable}

Preoperative variables

Age, year

$66[61-71]$

$\mathrm{BMI}, \mathrm{kg} / \mathrm{m}^{2}$

$24.6[22.8-26.2]$

ASA physical status, $\mathrm{n}$

।

$436(33.3 \%)$

II

$829(63.2 \%)$

III

$46(3.5 \%)$

Smoker, $\mathrm{n}$

490 (37.4\%)

Preoperative PSA, ng/ml

8.9 [5.6-15.8]

Preoperative $\mathrm{Hb}, \mathrm{g} / \mathrm{dl}$

14.6 [13.8-15.4]

Preoperative Hct, \%

42.8 [40.4-44.9]

Year

2007-2008

$196(15.0 \%)$

2009-2010

$372(28.4 \%)$

2011-2012

$377(28.8 \%)$

2013-2014

$366(27.9 \%)$

Intraoperative variables

Main anesthetic agent, $\mathrm{n}$

Inhalation agent

$1217(92.8 \%)$

Propofol

$94(7.2 \%)$

Fluid administered

Crystalloid, ml

1204 [900-1651]

Estimated blood loss, $\mathrm{ml}$

200 [100-300]

Duration of surgery, min

200 [175-225]

Statistically significant $p$ value $(<0.05)$ are highlighted in bold. Values are expressed as median [interquartile range] or number (percentage). Abbreviations: BMI, Body mass index; ASA, American society of anesthesiologists; PSA, Prostate-specific antigen; Hb, hemoglobin; Hct, hematocrit; BCR, Biochemical recurrence. 


\section{Variable}

Duration of anesthesia, min

Perioperative transfusion

Patients who transfused, $\mathrm{n}$

Number of packed RBC in patients transfused

Pathological variables

Pathologic T stage, $\mathrm{n}$

pT2

pT2a

pT2c

рT3a

pT3b

pT4

Pathologic $N$ stage, $n$

$\mathrm{Nx}$

NO

N1

Gleason score, $n$

$\leq 6$

7

8

9

Surgical margin positive, $n$

Length of hospital stay, d

1 year BCR

5 year BCR
250 [225-275]

$30(2.3 \%)$

2 [2-3]

$3(0.2 \%)$

$109(8.3 \%)$

$771(58.8 \%)$

291 (22.2\%)

$129(9.8 \%)$

$8(0.6 \%)$

792 (60.4\%)

$486(37.0 \%)$

$33(2.5 \%)$

$116(8.8 \%)$

$1025(78.2 \%)$

$62(4.7 \%)$

$108(8.2 \%)$

$393(30.0 \%)$

11 [9-12]

79 (6.0\%)

$206(15.7 \%)$

Statistically significant $p$ value $(<0.05)$ are highlighted in bold. Values are expressed as median [interquartile range] or number (percentage). Abbreviations: BMI, Body mass index; ASA, American society of anesthesiologists; PSA, Prostate-specific antigen; Hb, hemoglobin; Hct, hematocrit; BCR, Biochemical recurrence. 
Table 2 shows the results of univariate and multivariate Cox proportional regression analysis for the 5year BCR. In univariate analysis, RBC transfusion was associated with the 5-year BCR (HR 2.159, 95\% Cl $1.107-4.211, p=0.024)$. The result also showed the significant association between the number of transfused RBC and 5-year BCR (HR 1.335, 95\% Cl 1.094-1.631, $p=0.005)$. However, when they were included in the multivariate analysis with preoperative PSA level, pathologic T stage, $\mathrm{N}$ stage, gleason score and surgical margin status, both variables were not statistically significant, respectively $(p>0.05)$. Other variables, including preoperative PSA (HR 1.005, 95\% Cl 1.002-1.009, $p<0.001$ ), pathologic $T$ stage $\geq$ pT3 (HR 3.510, 95\% Cl 2.426-5.078, $p<0.001)$, N stage (HR 2.337, 95\% Cl 1.465-3.729, $p<$ $0.001)$, Gleason score $\geq 8$ (HR 2.373, 95\% Cl 1.756-3.207, $p<0.001)$ and positive surgical margin (HR $2.010,95 \% \mathrm{Cl} 1.452-2.782, p<0.001)$ were found to be independent predictor of 5 -year BCR. 
Table 2

Univariate and Multivariate Cox proportional hazard regression analysis for 5-year biochemical recurrence of prostate cancer

\begin{tabular}{|c|c|c|c|c|}
\hline \multirow[t]{2}{*}{ Variable } & \multicolumn{2}{|l|}{ Univariate Analysis } & \multicolumn{2}{|c|}{ Multivariate Analysis } \\
\hline & $\mathrm{HR}(95 \% \mathrm{Cl})$ & $p$-value & $\mathrm{HR}(95 \% \mathrm{Cl})$ & $p$-value \\
\hline \multicolumn{5}{|l|}{ Preoperative variables } \\
\hline Age, year & $1.015(0.994-1.035)$ & 0.155 & & \\
\hline $\mathrm{BMI}, \mathrm{kg} / \mathrm{m} 2$ & $0.991(0.951-1.034)$ & 0.678 & & \\
\hline \multicolumn{5}{|l|}{ ASA physical status } \\
\hline I & 1 (reference) & & & \\
\hline II & $0.794(0.597-1.056)$ & 0.112 & & \\
\hline III & $0.934(0.451-1.934)$ & 0.854 & & \\
\hline Diabetes mellitus & $1.321(0.887-1.968)$ & 0.171 & & \\
\hline Hypertension & $1.188(0.887-1.592)$ & 0.248 & & \\
\hline Coronary artery disease & $1.421(0.840-2.404)$ & 0.190 & & \\
\hline Cerebrovascular accident & $1.382(0.651-2.937)$ & 0.400 & & \\
\hline Smoker & $0.933(0.702-1.241)$ & 0.634 & & \\
\hline Preoperative PSA, ng/ml & $1.015(1.013-1.018)$ & <. $001 *$ & $\begin{array}{l}1.005(1.002- \\
1.009)\end{array}$ & $\begin{array}{l}<.001 * \\
0.00\end{array}$ \\
\hline Preoperative $\mathrm{Hb}, \mathrm{g} / \mathrm{dl}$ & $0.916(0.826-1.016)$ & 0.098 & & \\
\hline \multicolumn{5}{|l|}{ Intraoperative variables } \\
\hline \multicolumn{5}{|l|}{ Main anesthetic agent } \\
\hline Inhalation agent & 1 (reference) & & & \\
\hline Propofol & $0.957(0.556-1.646)$ & 0.874 & & \\
\hline Crystalloid, ml & $1.000(1.000-1.000)$ & 0.968 & & \\
\hline Colloid, ml & $1.000(1.000-1.001)$ & $0.034^{*}$ & & \\
\hline Estimated blood loss, ml & $1.001(1.000-1.001)$ & $0.042^{*}$ & & \\
\hline $\begin{array}{l}\text { Perioperative RBC } \\
\text { transfusion }\end{array}$ & & & & \\
\hline
\end{tabular}

Statistically significant $p$ value $(<0.05)$ are highlighted in bold. Abbreviations: BMI, Body mass index; ASA, American society of anesthesiologists; PSA, Prostate-specific antigen; Hb, hemoglobin; Hct, hematocrit. 


\begin{tabular}{|c|c|c|c|c|}
\hline Variable & Univariate Analysis & \multicolumn{3}{|c|}{ Multivariate Analysis } \\
\hline None & \multicolumn{2}{|l|}{1 (reference) } & \\
\hline Transfusion & $2.159(1.107-4.211)$ & \multicolumn{3}{|l|}{$0.024^{*}$} \\
\hline Number of packed RBC & $1.335(1.094-1.631)$ & \multicolumn{3}{|l|}{$0.005^{*}$} \\
\hline \multicolumn{5}{|l|}{ Pathological variables } \\
\hline \multicolumn{5}{|l|}{ Pathologic T stage } \\
\hline$<$ pT3 & \multicolumn{4}{|l|}{1 (reference) } \\
\hline$\geq$ pT3 & 7.197 (5.264-9.839) & $\begin{array}{l}<.001 * \\
0.00\end{array}$ & $\begin{array}{l}3.510(2.426- \\
5.078)\end{array}$ & ¿.001* \\
\hline \multicolumn{5}{|l|}{ Pathologic N stage } \\
\hline Nx or NO & \multicolumn{4}{|l|}{1 (reference) } \\
\hline N1 & $\begin{array}{l}7.080(4.504- \\
11.129)\end{array}$ & $\begin{array}{l}<.001 * \\
0.00\end{array}$ & $\begin{array}{l}2.337(1.465- \\
3.729)\end{array}$ & <.001* \\
\hline \multicolumn{5}{|l|}{ Gleason score } \\
\hline$<8$ & \multicolumn{4}{|l|}{1 (reference) } \\
\hline$\geq 8$ & $5.478(4.137-7.254)$ & $\begin{array}{l}<.001 * \\
0.00\end{array}$ & $\begin{array}{l}2.373(1.756- \\
3.207)\end{array}$ & <.001* \\
\hline Surgical margin positive & $4.821(3.628-6.404)$ & $\begin{array}{l}<.001 * \\
0.00\end{array}$ & $\begin{array}{l}2.010(1.452- \\
2.782)\end{array}$ & <.001* \\
\hline \multicolumn{5}{|c|}{$\begin{array}{l}\text { Statistically significant } p \text { value }(<0.05) \text { are highlighted in bold. Abbreviations: BMI, Body mass index; } \\
\text { ASA, American society of anesthesiologists; PSA, Prostate-specific antigen; } \mathrm{Hb} \text {, hemoglobin; Hct, } \\
\text { hematocrit. }\end{array}$} \\
\hline
\end{tabular}

\section{Discussion}

This study showed that perioperative transfusion was not independent factor for 5-year BCR in patients undergoing RARP. In addition, this study found that pathologic T stage, N stage, Gleason score, and surgical margin were independently associated with an increased 5-year BCR.

Several studies focused on how transfusion causes pro-tumorigenic environment and supported a significant association between transfusion and increased recurrence in patients undergoing surgery for colon, stomach, liver, or bladder cancer [10-13]. There are several pathophysiology to explain the effect of blood transfusion on tumor recurrence in patients undergoing cancer surgery. Surgical manipulation may enable malignant cells to circulate in the bloodstream [14, 15]. Moreover, anesthetics and opioids attenuate host immunity, leading to a permissive tumor environment [16]. Indeed, previous work assessed perioperative changes in the ratio of Th1/Th2 cells period in surgical patients, and observed a shift 
toward a Th2 immune response, indicative of a significant alteration in the composition of the immune system [17]. Post-surgical immunosuppression may be further aggravated by transfusion as RBCs can also modulate the immune system, a phenomena referred to as transfusion related immunomodulation (TRIM). There are 4 mechanisms for TRIM; 1 ) suppression of cytotoxic cell and monocyte activity; 2 ) release of immunosuppressive prostaglandins; 3 ) inhibition of interleukin-2 production; 4) increased suppressor T-cell activity [18]. Contrary to those studies, we found that transfusion was not associated with increased 5-year BCR in patients undergoing RARP.

In the present study, the average patient blood loss was $200 \mathrm{ml}$, and transfusion rate was $2.3 \%$. These are comparable to previous work which showed that RARP reduced blood loss ( $188 \mathrm{ml}$ vs. $745 \mathrm{ml}$ ) and transfusion rates (16.5\% vs. $1.8 \%$ ) when compared with open prostatectomy [19]. Among the patients who received blood transfusion, the median number of transfused RBC was 2 units. Given that relatively low blood loss and volume, it can be inferred that the volume of transfused RBC was not enough to induce pro-tumor environment or immunomodulation.

Consistent with previous work, this study showed that Gleason score, T stage, N stage, and surgical margin, were independent predictors of 5-year BCR. Several large studies with a follow-up more than 5 years have identified predictors of BCR after RARP [7, 20-22]. Despite slightly different definitions of variables among these studies, most studies have reported that Gleason score, pathologic stage, and/or surgical margin were independently associated with 5-year BCR.

It is important to recognize that BCR is not a definitive indicator for the clinical relapse of prostate cancer. However, BCR has been associated with increased mortality [23]. Therefore, physicians should be aware of predictive factors for BCR in prostate cancer patients, and therein stratify high risk patients to prevent clinical progression.

There are several limitations in this study. First, transfusion was performed in accordance with conventional criteria but without a predefined protocol. Given that our results are based on a retrospective analysis, further prospective studies are therefore required to validate the association between transfusion and 5-year BCR. Second, the impact of RBC storage was not considered in this study. It has been reported that prolonged RBC storage may have detrimental clinical impacts [24]. However, the small number of patients who were transfused in this study was seemingly insufficient to draw meaningful results from a subgroup analysis based on the duration of RBC storage.

\section{Conclusion}

The evidence from this study suggests that blood transfusion was not associated with an increased 5year BCR in patients undergoing RARP. We hope that our research will be helpful in terms of perioperative blood management in patients undergoing RARP.

\section{Declarations}


Ethics approval and consent to participate

This study was conducted according to the guidelines of the Declaration of Helsinki, and approved by the Institutional Review Board of Seoul National University Bundang Hospital (No. B-2005/615-105 and approval date: May 20,2020). Patient consent was waived due to the retrospective design.

Consent for publication

Not applicable

Availability of data and materials

The datasets generated and analyzed during the current study are available from the corresponding author on reasonable request.

Competing interests

The authors declare that they have no competing interests

\section{Funding}

No funding received

\section{Authors' contributions}

J.H. and C-.H.K. wrote the main manuscript text, Y-.T.J and C-.H.K. developed protocol and edit the manuscript, J-.H.R. managed and analyzed data, A-Y.O., H.K. and Y.K.B. collected and analyzed data. All authors reviewed the manuscript.

Acknowledgements

Not applicable

\section{References}

1. Mottrie A, De Naeyer G, Novara G, Ficarra V. Robotic radical prostatectomy: a critical analysis of the impact on cancer control. Curr Opin Urol. 2011;21(3):179-84.

2. Gandaglia G, Sammon JD, Chang SL, Choueiri TK, Hu JC, Karakiewicz PI, et al. Comparative effectiveness of robot-assisted and open radical prostatectomy in the postdissemination era. $\mathrm{J}$ Clin Oncol. 2014;32(14):1419-26.

3. Murphy DG, Kerger M, Crowe H, Peters JS, Costello AJ. Operative details and oncological and functional outcome of robotic-assisted laparoscopic radical prostatectomy: 400 cases with a minimum 
of 12 months follow-up. Eur Urol. 2009;55(6):1358-66.

4. Novara G, Ficarra V, Mocellin S, Ahlering TE, Carroll PR, Graefen M, et al. Systematic review and meta-analysis of studies reporting oncologic outcome after robot-assisted radical prostatectomy. Eur Urol. 2012;62(3):382-404.

5. Okegawa T, Omura S, Samejima M, Ninomiya N, Taguchi S, Nakamura Y, et al. Laparoscopic radical prostatectomy versus robot-assisted radical prostatectomy: comparison of oncological outcomes at a single center. Prostate Int. 2020;8(1):16-21.

6. McCormick BZ, Mahmoud AM, Williams SB, Davis JW. Biochemical recurrence after radical prostatectomy: Current status of its use as a treatment endpoint and early management strategies. Indian J Urol. 2019;35(1):6-17.

7. Liss MA, Lusch A, Morales B, Beheshti N, Skarecky D, Narula N, et al. Robot-assisted radical prostatectomy: 5-year oncological and biochemical outcomes. J Urol. 2012;188(6):2205-10.

8. Carroll PR, Parsons JK, Andriole G, Bahnson RR, Barocas DA, Castle EP, et al. NCCN Clinical Practice Guidelines Prostate Cancer Early Detection, Version 2.2015. J Natl Compr Canc Netw. 2015;13(12):153461.

9. Pushan Z, Manbiao C, Sulai L, Jun L, Ruidong Z, Hanshen Y. The impact of perioperative blood transfusion on survival and recurrence after radical prostatectomy for prostate cancer: A systematic review and meta-analysis. J Cancer Res Ther. 2018;14(Supplement):S701-S7.

10. Amato A, Pescatori M. Perioperative blood transfusions for the recurrence of colorectal cancer. Cochrane Database Syst Rev. 2006(1):CD005033.

11. Linder BJ, Frank I, Cheville JC, Tollefson MK, Thompson RH, Tarrell RF, et al. The impact of perioperative blood transfusion on cancer recurrence and survival following radical cystectomy. Eur Urol. 2013;63(5):839-45.

12. Makino Y, Yamanoi A, Kimoto T, El-Assal ON, Kohno H, Nagasue N. The influence of perioperative blood transfusion on intrahepatic recurrence after curative resection of hepatocellular carcinoma. Am J Gastroenterol. 2000;95(5):1294-300.

13. Squires MH, 3rd, Kooby DA, Poultsides GA, Weber SM, Bloomston M, Fields RC, et al. Effect of Perioperative Transfusion on Recurrence and Survival after Gastric Cancer Resection: A 7-Institution Analysis of 765 Patients from the US Gastric Cancer Collaborative. J Am Coll Surg. 2015;221(3):767-77.

14. Bosch B, Guller U, Schnider A, Maurer R, Harder F, Metzger U, et al. Perioperative detection of disseminated tumour cells is an independent prognostic factor in patients with colorectal cancer. $\mathrm{Br} \mathrm{J}$ Surg. 2003;90(7):882-8. 
15. Yamaguchi K, Takagi Y, Aoki S, Futamura M, Saji S. Significant detection of circulating cancer cells in the blood by reverse transcriptase-polymerase chain reaction during colorectal cancer resection. Ann Surg. 2000;232(1):58-65.

16. Ash SA, Buggy DJ. Does regional anaesthesia and analgesia or opioid analgesia influence recurrence after primary cancer surgery? An update of available evidence. Best Pract Res Clin Anaesthesiol. 2013;27(4):441-56.

17. Ishikawa M, Nishioka M, Hanaki N, Miyauchi T, Kashiwagi $\mathrm{Y}$, loki $\mathrm{H}$, et al. Perioperative immune responses in cancer patients undergoing digestive surgeries. World J Surg Oncol. 2009;7:7.

18. Cata JP, Wang H, Gottumukkala V, Reuben J, Sessler DI. Inflammatory response, immunosuppression, and cancer recurrence after perioperative blood transfusions. $\mathrm{Br} \mathrm{J}$ Anaesth. 2013;110(5):690-701.

19. Tewari A, Sooriakumaran P, Bloch DA, Seshadri-Kreaden U, Hebert AE, Wiklund P. Positive surgical margin and perioperative complication rates of primary surgical treatments for prostate cancer: a systematic review and meta-analysis comparing retropubic, laparoscopic, and robotic prostatectomy. Eur Urol. 2012;62(1):1-15.

20. Menon M, Bhandari M, Gupta N, Lane Z, Peabody JO, Rogers CG, et al. Biochemical recurrence following robot-assisted radical prostatectomy: analysis of 1384 patients with a median 5-year follow-up. Eur Urol. 2010;58(6):838-46.

21. Sooriakumaran P, Haendler L, Nyberg T, Gronberg H, Nilsson A, Carlsson S, et al. Biochemical recurrence after robot-assisted radical prostatectomy in a European single-centre cohort with a minimum follow-up time of 5 years. Eur Urol. 2012;62(5):768-74.

22. Suardi N, Ficarra V, Willemsen P, De Wil P, Gallina A, De Naeyer G, et al. Long-term biochemical recurrence rates after robot-assisted radical prostatectomy: analysis of a single-center series of patients with a minimum follow-up of 5 years. Urology. 2012;79(1):133-8.

23. Uchio EM, Aslan M, Wells CK, Calderone J, Concato J. Impact of biochemical recurrence in prostate cancer among US veterans. Arch Intern Med. 2010;170(15):1390-5.

24. Tinmouth A, Fergusson D, Yee IC, Hebert PC, Investigators A, Canadian Critical Care Trials G. Clinical consequences of red cell storage in the critically ill. Transfusion. 2006;46(11):2014-27.

\section{Figures}


Patients underwent robot-assisted laparoscopic radical prostatectomy between October 2007 and December 2014

$$
(n=1341)
$$

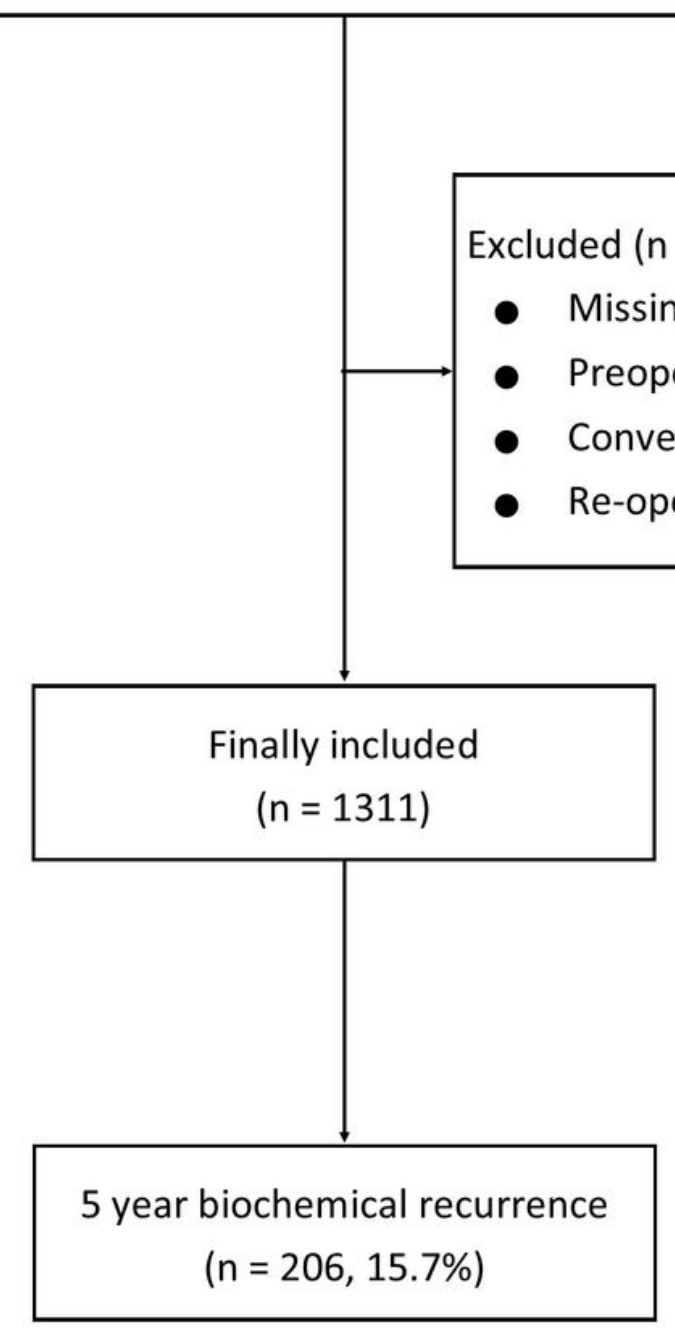

\section{Figure 1}

Flow diagram outlining the inclusion and exclusion criteria with assignment of study cohort. 